This is a post-peer-review, pre-copyedit version of an article published in Philosophia. The final authenticated version is available online at: https://doi.org/10.1007/s11406-021-00368-w

\title{
Blame Without Punishment for Addicts
}

\author{
Prabhpal Singh
}

\begin{abstract}
On the moral model of addiction, addicts are morally responsible and blameworthy for their addictive behaviours. The model is sometimes resisted on the grounds that blaming addicts is incompatible with treating addiction in a compassionate and non-punitive way. I argue the moral model is consistent with addressing addiction compassionately and non-punitively and better accounts for both the role of addicts' agency in the recovery process. If an addict is responsible for their addictive behaviours, and that behaviour is in some way bad or wrong, then that addict is blameworthy. If not, then they are not. But, if their addictive behaviour or behaviour which contributes to and perpetuates their condition of addiction, is not bad or wrong, then addiction is not an issue of moral concern. Addicts are blameworthy, but attributions of blame need not be followed by harsh treatment or punishment. Because blame and harsh treatment or punishment can be separated, there is no good reason to reject the moral model of addiction.
\end{abstract}

Keywords: Addiction, Responsibility, Blame, Punishment

\section{Introduction}

The moral model of addiction, on which addicts are morally responsible and blameworthy, is often rejected because it seems too harsh, treats addicts as if they were necessarily bad people, and invites negative reactive attitudes and punishments towards addicts. Those who reject the moral model seek to avoid a view that blames addicts and invites harsh treatment or punishment. For example, Hanna Pickard (2017) has argued against the moral model of addiction in favour of a model that preserves moral responsibility for addicts but jettisons blaming them. An advantage of this sort of view is that it is meant to provide greater instrumental value in addressing addiction in clinical care contexts and as a public health issue. For those who reject the moral model, blaming addicts is of negative instrumental value in achieving public health and clinical care goals, and this is taken as a reason for rejecting the model.

In this paper, I argue the moral model of addiction on which addicts are morally responsible and blameworthy for their addictive behaviour is consistent with compassionate and non-punitive responses to addressing addiction as a public health issue. Blaming addicts for their addictive 
This is a post-peer-review, pre-copyedit version of an article published in Philosophia. The final authenticated version is available online at: https://doi.org/10.1007/s11406-021-00368-w

behaviours helps rather than hurts the project of proper clinical care if that project aims to help addicts recover. Efforts to move away from the moral model are thus unnecessary. There is no good reason to abandon the moral model of addiction, as there is no good reason to think holding addicts responsible and blameworthy for their actions interferes with understanding addiction as a public health issue and addressing it with compassion. Further, blaming addicts can help rather than hurt efforts to address addiction and assist addicts in overcoming their addictions. To show this, I consider the function of blame and the attribution of blameworthiness to an addict's behaviour. I then explain how both an addict's blameworthiness and any attributions of blame are needed for the project of addressing addiction as a public health issue with proper care. We can blame addicts for their addictive behaviour while still responding to addiction compassionately rather than with punishment or harsh treatment. This is because blame can play a communicative role in engaging addicts' agency when it comes to overcoming their addictions.

\section{Responsibility, Blame, and Harsh Treatment}

One strong case against the moral model of addiction comes from Hanna Pickard (2017). Pickard describes the moral model of addiction as having two components. First, it regards addictive behaviours as choices, even for addicts. Second, it takes a critical moral stance against these choices. Because addictive behaviour on the moral model is a choice, those who make such choices are morally responsible for them. And because addictive choices are condemnable choices, those who make those choices are blameworthy.

Pickard argues addicts can be held morally responsible for their choice to feed their addiction, but that this can be done without attributions of blame. Pickard states, "Just as addicts have choices with respect to drug use, we have choices with respect to how we respond to people who use drugs" (Pickard 2017,173). Pickard's idea is that even if we take the addict's choice to 
This is a post-peer-review, pre-copyedit version of an article published in Philosophia. The final authenticated version is available online at: https://doi.org/10.1007/s11406-021-00368-w

feed their addiction to be morally wrong, we need not blame the addict for their choice. So, Pickard preserves the notion of moral responsibility for addicts for their choices but denies they are blameworthy.

Pickard advances her case by distinguishing between responsibility and blame. Pickard notes that the notion of responsibility has long been considered tied to morality $(2017,174)$. By tying together responsibility and moral evaluation, it becomes easy to see how one may arrive at the moral model. Pickard points out such moral evaluations often take the form of negative affective reactive attitudes $(2017,174)$. These include but are not limited to anger, resentment, hate, indignation, disgust, revulsion, contempt, and scorn. When based on negative reactive attitudes, actions to address addiction are likely to be just as hostile. So, if the moral model of addiction is taken seriously, then it is impossible to address addiction as a public health issue with compassion, or so Pickard argues. This is because if an addict is morally responsible, then their relevant actions and choices are subject to moral evaluation. But because these evaluations take the form of negative reactive attitudes, addicts are often subject to attitudes of anger, resentment, hate, indignation, disgust, revulsion, contempt, and scorn. By tying responsibility closely to morality and moral evaluation, there seems to be no room for compassion given the negative reactive attitudes that surround addiction, and only room for blame.

For Pickard, the purpose of clinical practice is to care for patients and help them recover (2017, 175). But in the case of addiction, the goal of recovery is not served by blaming patients, even when they are responsible. So, we can hold addicts morally responsible, but set aside attributions of blame by focusing on the purpose of clinical practice. By focusing on caring for the patient, addiction can be addressed with compassion, free from blame, negative reactive attitudes, and harsh treatment or punishment. 
This is a post-peer-review, pre-copyedit version of an article published in Philosophia. The final authenticated version is available online at: https://doi.org/10.1007/s11406-021-00368-w

\section{Separating Blame and Harsh Treatment}

Pickard's rejection of the moral model is based on pragmatic reasons relevant to clinical practice. For the sake of proper clinical practice, negative reactive attitudes and blame are to be set aside and replaced with compassion. In describing the moral model, Pickard states:

Because the moral model of addiction sees drug use as a choice, it views addicts as responsible; because it condemns this choice, it views them as to blame - potentially deserving of the stigma and harsh treatment they in fact receive (Pickard 2017, 170).

This account of blame entangles attributions of blame with deservingness of harsh treatment, stigma, or punishment. So, on this view of blame, blame is necessarily accompanied by attitudes of deservingness of harsh treatment or punishment and is thus instrumentally dis-valuable for clinical care's goal of recovery. However, this is a mistake. Blaming addicts need not get in the way of proper clinical care that aims at recovery. This is because attributions of blame need not accompany negative reactive attitudes that affect how addiction is responded to. Addicts can be blameworthy but still receive the care they need without harsh treatment or punishment. Further, while blame should not get in the way of proper clinical care, it will have to be attributed at some point if clinical care aims to absolve an addict of their addiction.

Attribution of blame is the attribution of the conjunction of an agent's responsibility for a choice or action and the wrongness of that choice or action. A choice or action is blameworthy when it meets two conditions: First, the choice or action must be bad or wrong in a normative sense. Second, the choice or action must belong to the agent in the relevant sense of 'belong' for attributions of responsibility. When an addict is responsible for their addictive behaviour and that behaviour is wrong, they are blameworthy. If addiction is something that needs to be addressed, say, as a personal or public health issue, then it seems likely to be bad or wrong in some normative 
This is a post-peer-review, pre-copyedit version of an article published in Philosophia. The final authenticated version is available online at: https://doi.org/10.1007/s11406-021-00368-w

sense. If addiction were not bad or in some normative sense, then there would be no moral reasons for it to be addressed. The fact that addressing addiction will require addicts to own up to their choices in a way that suggests a degree of agency and responsibility implies the addict's addictive behaviour belongs to them in the relevant sense. Therefore, an addict's addictive behaviour meets the conditions for blameworthiness.

A model of responsibility and blame for addicts like Pickard's separates moral responsibility from blameworthiness but entangles the negative reactive attitudes of blame with harsh treatment. However, I suggest the separation not be between moral responsibility and blame, but between blame and harsh treatment. Moral responsibility and blame are kept while strong negative reactive attitudes that would motivate harsh treatment or punishment are abandoned. Addicts are held morally responsible for their addictive behaviour and are blameworthy but are also to be treated with proper care, with compassion, and without negative reactive attitudes that motivate harsh treatment or punishment.

The primary concern with blaming addicts is that it gets in the way of proper clinical care. However, if we consider how addiction is overcome, we shall see that blame is in an important way instrumentally valuable in addressing addiction as a public health issue. Addicts must at some point choose to cease their addictive behaviour. On the choice model, addicts do have a degree of agency and therefore bear some responsibility for their actions ${ }^{1}$. Addicts have agency and

\footnotetext{
${ }^{1}$ A reviewer points out that this would not apply to a case in which a baby is born with an addiction due to their biological mother's addiction. Like Pickard, my discussion focuses on the relationship between blame and punishment on the choice model. Those approaching addiction with the choice model must say that babies born with addictions cannot be held morally responsible because have made no choices that have led them to suffering addiction. This means that the question of whether they are blameworthy does not apply if operating with the choice model of addiction. Inquiring into the nature of addictions that are not brought about by the choices of the addicted agent would require an alternative model to operate, but discussion of such a model far exceeds the scope of this paper.
} 
This is a post-peer-review, pre-copyedit version of an article published in Philosophia. The final authenticated version is available online at: https://doi.org/10.1007/s11406-021-00368-w

responsibility in both beginning and ending their condition of addiction. This is due to addiction arising in part due to the choices and actions of agents that become addicts. Agents that become addicts at some point choose to and successfully engage in some behaviour that contributes to the formation of addiction (for example, the choice to use certain substances, such as drugs). But when their addictive choices or actions are wrong, they become blameworthy. If their addictive choices or actions were not wrong, then addicts would not be blameworthy, for in the absence of wrongness there is nothing to blame them for. In this way, blame is conceptually inseparable from responsibility because to be blameworthy is to be responsible for a moral wrong. Consider that if certain addictive choices or actions were not wrong, there would be no sense in making any sort of effort in addressing it as a public health issue. Presumably, addiction is to be addressed as a public health issue on moral grounds. From a public health perspective, the interest is in addressing illnesses, and it is not morally wrong to be ill. But the case of addiction has an additional dimension. It is an illness that is brought about in significant part due to an agent's choices and actions where these choices and actions are often wrong. This is because addictive choices and actions that contribute to and perpetuate the condition of addiction often lead to severe harm to both the addict and the people around them (Pickard 2017, 177). Additionally, addiction is a condition that affects an agent's ability to evaluate properly the value of their addictive behaviour. Jesse S. Summers (2015) argues this 'misvaluation' of the worth of addictive behaviour on the part of the addict is the specific wrong of addiction. For Summers, the effects on an agent's ability to properly evaluate the worth of addictive behaviour are partially what explains what addiction as a condition is $(2015,34-35)$. In this way, addiction is by its nature wrong. For these reasons, it is clear to see those addictive behaviours are wrong either by the severe harms they lead to or by their impact on an agent's ability to properly evaluate their worth. Addiction is thus different than 
This is a post-peer-review, pre-copyedit version of an article published in Philosophia. The final authenticated version is available online at: https://doi.org/10.1007/s11406-021-00368-w

other public health concerns. While other public health concerns may be primarily about addressing threats to health that may not include a moral dimension, addiction is one such public health issue that necessarily involves people's agency, and so possesses a moral dimension that separates it from other public health issues. In this way, addiction is both, a public health and moral issue.

Importantly, addicts are not blamed for merely being addicts. That is, addicts are not blameworthy in virtue of merely having the condition of being addicted. As mentioned, it is not a moral failing to merely be ill. Instead, addicts are blameworthy for their choices and actions which contribute to and perpetuate their condition of addiction that results in harm to themselves and others around them.

Addicts' blameworthiness is dependent upon the wrongness of the harms of their addictive choices and actions. To say addicts are not blameworthy is to say they have not done anything wrong, as wrongdoing is a requisite condition of blameworthiness. But addiction both causes morally significant harm and is caused and perpetuated by an agent's choices and actions. This sort of harm constitutes wrongdoing. And because addicts are morally responsible for their choices, they meet the conditions for blame. While blame is culpable wrongdoing and is often connected to harsh treatment or punishment, this is not a necessary connection. If we want to end the problematic behaviour of addictions and the best way to do that is with care rather than punishment, then blame and care are perfectly consistent.

\section{Blame and Agency}

One may object that the wrong of addiction is not an agential wrong, but a non-moral wrong. On this view, the 'wrong' of addiction is not a moral wrong in the sense of a culpable wrong action. Instead, it is more like a wrong state of affairs. Murder, for example, is a moral wrong, whereas, 
This is a post-peer-review, pre-copyedit version of an article published in Philosophia. The final authenticated version is available online at: https://doi.org/10.1007/s11406-021-00368-w

say, a natural disaster is a non-moral wrong. Murder is a morally wrong action that ought not to be done, whereas natural disasters are things out of any agent's direct control and we might think them things that in a different sense ought not to happen (due to the damage and destruction they cause, for example). Addiction is more like a natural disaster that dominates the will of the addict, so the addict cannot be blameworthy for the choices they make. The purpose of proper clinical care is to address the condition of addiction as distinct from the will and actions of the addict. However, this supposes that addiction is detached from the choices of the addict. We have seen that both the nature and wrongness of addiction are intimately connected with the addict's will and actions. If addictive behaviours are choices, then addictive impulses are not puppet strings controlling the addict. If addiction functions like puppet strings, controlling and influencing the addicts, then the addict is their own puppet master. To address addiction as a condition requires addressing the addict's choices. Specifically, it requires addressing the addict's wrong choices to engage in addictive behaviours. Because the addict's addictive choices are both their responsibility and wrong, addicts are blameworthy for their addictive choices and actions.

Thus, because addictive behaviour is wrong, and addicts are morally responsible for choosing addictive behaviour, they are blameworthy. But such blame need not be accompanied by harsh treatment. Attributions of blame are important for properly caring for addicts and helping them to recover. This is because attributions of blame recognize an addict's condition and involving choices and actions for which they are responsible, and thus recognize the addict's agency. The function of blame is to add weight to the addict's action by communicating their choices as both their responsibility and wrongs that need to be corrected. Blame is action-guiding because it is a normatively loaded attribution. To be properly blameworthy, an agent must have done something wrong. When addicts are blamed, they are being told that their addictive 
This is a post-peer-review, pre-copyedit version of an article published in Philosophia. The final authenticated version is available online at: https://doi.org/10.1007/s11406-021-00368-w

behaviours fall within the set of their choices for which they are morally responsible and that those are not the choices they ought to make. By attributing blame to addicts for their addictive behaviour, addicts get the message that their actions are wrong and need to be corrected.

Thus, blame plays a communicative and action-guiding role. It is communicative because its meaning is about the wrongness of the addict's actions. It is action-guiding because the attribution of wrongness means the addict's current actions need to change. Without knowing they have a problem that needs to be corrected, no addict can choose to overcome their addiction, for their addiction would not be viewed as a problem needing to be overcome. In this way, blame has instrumental value for properly caring for addicts to help them overcome their addictions.

By informing addicts of the wrongness of their actions, the addict's agency is enhanced. To begin the journey of recovery, they must at some point come to recognize abandoning their addictive behaviours and overcoming their addiction counts as a recovery rather than mere change. Recognition of the wrongness of their actions can be the first step for an addict who takes on the project of overcoming their addiction. To describe something as a thing to be overcome carries with it some normative valence. It suggests a normatively problematic situation needing to be improved. Without recognizing their condition as a morally problematic one, addiction in the mind of the addict is not something to be overcome. Thus, instilling within addicts a sense of the wrongness of their actions, such as through blame, enhances an addict's agency as it pertains to the project of overcoming their addiction. This also means that any instances of holding addicts responsible and taking their addictive behaviours to be wrong would count as an attribution of blame. Thus, the moral model of addiction is not only consistent with proper care for addicts, but it can also positively contribute to the success of addressing addiction by highlighting the addict's role in their recovery process. 
This is a post-peer-review, pre-copyedit version of an article published in Philosophia. The final authenticated version is available online at: https://doi.org/10.1007/s11406-021-00368-w

\section{Abandon the Moral Model Anyway?}

Because the central motivation against the moral model is to avoid harsh treatment toward addicts, as such treatment gets in the way of proper care, one may object to my view on the grounds that blame carries a stigma, meaning blaming addicts would stigmatize them and their conditions. Such stigmatization can interfere with proper care by reducing sympathy and compassion for addicts and by creating strong negative psychological states for addicts themselves. When addiction is stigmatized it becomes more difficult to generate a sympathetic response to it from a public health perspective. When addicts are dejected and demoralized, recovery becomes near impossible and a path toward the development and exacerbation of other mental health issues, and the accompanying risks of these mental health issues, opens. So, while addicts may be blameworthy in virtue of them being responsible for their wrong addictive behaviour, blaming does not help to address addiction sympathetically. The stigmatization of being blameworthy means blaming addicts hurts them rather than helps them, so the moral model needs to be abandoned.

While it is true that stigmatization will be instrumentally dis-valuable for addressing addiction and helping addicts recover, the stigmatization of both addiction and blame is not a problem for the moral model as a philosophical position. If it is the case that addicts are morally responsible and blameworthy for their actions, then the conditions of the moral model are met. As I have argued, blame can help rather than hurt the project of helping addicts overcome their addictions. Stigmatization is a result of a misunderstanding of what blame is and what being blameworthy means. Those who blame and stigmatize will still be combining blame with harsh treatment, which I have explained are a separable pair. Addicts who become dejected and demoralized in the face of blame are either failing to accept the wrong of their behaviour or the fact of their responsibility for their addictive behaviour. Both those who would stigmatize addicts 
This is a post-peer-review, pre-copyedit version of an article published in Philosophia. The final authenticated version is available online at: https://doi.org/10.1007/s11406-021-00368-w

and addicts who become dejected and demoralized in the face of blame fail to understand the nature of blame. This is because unsympathetic blamers mistakenly take blame to be necessarily connected to punishment and harsh treatment, whereas addicts who cannot handle being blamed are not owning up to their addictive behaviour and the need for them to address it. So, the threat of stigmatization is not a problem for the moral model. Instead, it reflects people's misunderstanding of blame as necessitating harsh treatment or punishment.

One could accept that the moral model is fine as a philosophical position but push back on the grounds that how the view is understood is more relevant to the practical matter of addressing addiction than is defending it on philosophical grounds. How blame is understood in a public setting is more pertinent to addressing addiction than is the correct philosophical account of addiction. The moral model could be the correct model of addiction, but it may nevertheless still be better to abandon it. Because punishment, harsh treatment, and stigmatization are so commonly associated with blame, it would be too much work to re-train the public's philosophical understanding of blame to match the moral model. So, while the moral model may be philosophically defensible, it is not practically useful because too many people associate blame with harsh treatment and re-training them to think otherwise is much more trouble than it is worth.

This sort of objection does not show the moral model to be false but gives different reasons for why it might be abandoned. It may be that addressing addiction with a false model of addiction may better help achieve public health goals. But the problem with abandoning the moral model is that it deprives the addict of the opportunity to properly confront their addiction. Again, because being blameworthy means being morally responsible for a wrong, and addicts meet this criterion, if we abandon the moral model, addicts do not have the opportunity to take responsibility for their wrong actions. By abandoning the moral model, we are either abandoning moral responsibility on 
This is a post-peer-review, pre-copyedit version of an article published in Philosophia. The final authenticated version is available online at: https://doi.org/10.1007/s11406-021-00368-w

the part of the addict or abandoning an addict's blameworthiness, or both. To abandon the notion that addicts are morally responsible for their addictive behaviour seems to get the nature of addictive behaviour wrong. To abandon blame means to abandon the wrongness of addictive behaviour, which makes addressing addiction pointless because if addictive behaviour is not in some sense wrong, addiction is not something that needs to be addressed. Because addicts must at some point choose to overcome their addiction, they must come to realize that their addiction is something that needs to be overcome. This means communicating to them that their addictive behaviour is wrong and that they are responsible for both choosing to engage in it and choosing to overcome it.

Just as an addict is blameworthy for engaging in their addictive behaviour, they are praiseworthy when they overcome their addiction. If addicts were not blameworthy, they could not be praiseworthy for overcoming their addiction. Recovery from addiction would be something out of the addict's control but we know this to not be the case. Addicts must choose to seek help, where this choice is a meaningful exercise of their agency. Also, it is their will and ability to choose to refrain from their addictive behaviour that plays a crucial role in the recovery process. The process of recovery is a demonstration of the addict's agency. The presence of agency is what makes it possible for an addict to be blamed or praised. The fact that some addicts do recover from their addictions shows addicts have sufficient agency for blame and praise. Because agency is central to the recovery process, it is essential to proper care for agents. On the moral model, addicts have the sort of agency required to make choices for which they would be blameworthy or praiseworthy. Thus, the moral model captures something important for proper care for addicts.

One may resist the idea that blaming addicts as per the moral model is not instrumentally valuable because of any engagement with addicts' agency, as I argue, but instead that it is 
This is a post-peer-review, pre-copyedit version of an article published in Philosophia. The final authenticated version is available online at: https://doi.org/10.1007/s11406-021-00368-w

instrumentally valuable because blame provides negative inputs that manipulate an addict's behaviour toward the direction of overcoming their addiction. The idea would be that blame would act as negative reinforcement away from addictive behaviour and ultimately away from their addiction. I am skeptical of this as an instrumentally valuable aspect of the moral model. On this view, blame resembles shame more than it resembles what I am envisioning it to be here. I am taking blame to be directly engaged with an addict's agency and their ability to overcome their wrong behaviour, whereas attributions of shame seem to be more focused on the wrongness of the behaviour itself. Without engagement with an addict's agency, there is little path toward overcoming their wrong addictive behaviour. Furthermore, if negative reinforcement were effective in getting addicts to move away from their addictive behaviours, one would expect many addicts to easily overcome their addictions due to the strong negative reinforcement provided by the harmful effects of many addictions. In many cases, the continued harmful effects of addiction and addictive behaviour are not effective in aiding addicts in overcoming their addiction. This is why addiction is a public health issue.

While blame can often be accompanied by strong negative reinforcement, I have been arguing that the association between blame and negative reactive attitudes misleads efforts to address addiction because it fails to properly appreciate how attributing blame recognizes an addict's agency. It is this recognition of agency that distinguishes blame from shame or stigmatization. Shame and stigmatization are characterized more so by the negative reactive attitudes toward certain actions and behaviours. Because stigmatization is often accompanied by strong negative reactive attitudes, stigmatization's emotive dispositions seem to readily invite harsh treatment. This is not conducive to achieve public health goals related to addiction. However, as I argue, blame can be attributed without such negative reactive attitudes or harsh treatment. As 
This is a post-peer-review, pre-copyedit version of an article published in Philosophia. The final authenticated version is available online at: https://doi.org/10.1007/s11406-021-00368-w

mentioned, blame is the conjunction of moral responsibility and wrongdoing. To be truly blameworthy, one must be responsible for a wrong. But anything can be stigmatized, independently of its actual moral status. This is why blame is distinct from stigma, and why stigmatization is not instrumentally valuable in addressing addiction, but blame is. Recognition of agency is the first step to overcoming addiction, and, contrary to how blame is understood elsewhere, blame accomplishes this first step.

\section{From Theory to Practice: A Mission for Public Philosophy}

The most significant challenge for the moral model is not its theoretical merits. The biggest challenge for the moral model of addiction is getting the public to accept the distinction between blame and harsh treatment. While it could be said that a proper model of addiction needs to be action-guiding not only in a theoretical sense but in a practical sense as well, it must also be understood when a problem is a psychological one rather than a philosophical one. If it is the case that the moral model is too stigmatized to be accepted, and this stigmatization neutralizes any of the benefits of the model, then the model fails to be action-guiding in a way that supports the mission of addressing addiction as a public health issue. While opponents of the moral model see this as a reason to abandon the moral model of addiction, I suggest it may instead be an opportunity for the philosophical re-training of the public mind.

If addiction is to be addressed as a public health issue, being honest with the public should be a priority. As I have argued, addicts are blameworthy, but this need not get in the way of compassionate care. What does get in the way of compassionate care is ignorant, misguided, or illinformed public opinion. If addiction is to be addressed as a public health issue the public has a moral responsibility to be fair to addicts. What is fair is to blame addicts without punishing them. If the prevailing public opinion is one that fails to recognize this distinction, the proper response 
This is a post-peer-review, pre-copyedit version of an article published in Philosophia. The final authenticated version is available online at: https://doi.org/10.1007/s11406-021-00368-w

is to re-educate the public. Plans to address complex ethical issues cannot be subordinate to the uninformed, prejudiced, irrational, inconsistent, arbitrary whims of public opinion. Such plans must be principled and reasoned, especially when lives are at stake, such as the lives of vulnerable addicts. When such plans require public co-operation and are in tension with dominant public views, abandoning principle and reason is not the way to go. Instead, there must be efforts made to alter the dominant public view to be aligned with the relevant facts, reasons, and evidence. So, the issue of stigmatization has more to do with the shortcomings of public opinion than it does with the moral model.

How does the public become re-educated? I suggest this happens with public philosophy. Philosophers need to be placed in public-facing positions where they directly explain how addicts are responsible for their addictive behaviours, are blameworthy, but need not be punished. This not so say philosophers should take over for public health officials. Instead, philosophers should step up as experts in a collaborative capacity to assist in the project of addressing addiction as a public health issue. Discussions of careful distinctions between relevant concepts should not be limited to the pages of academic essays. Having public discussions of philosophical conceptions of responsibility, blame, punishment, addiction, and the relationship between them is something philosophers can do to directly address public opinion that stigmatizes addiction and fails to distinguish between blame and punishment. By doing this, the public can be educated on the distinction between blame and punishment, thus reducing the stigmatization of addiction while maintaining the important role of blame in helping addicts to take responsibility for their recovery.

\section{Conclusion}


This is a post-peer-review, pre-copyedit version of an article published in Philosophia. The final authenticated version is available online at: https://doi.org/10.1007/s11406-021-00368-w

I have argued that the moral model of addiction on which addicts are morally responsible and blameworthy for their addictive behaviour is not only consistent with proper care for addicts but essential for such care. This is because blaming addicts for their addictive behaviour plays a communicative role in addressing their addiction. When an addict is blamed, they are being told they are responsible for their addictive behaviour and that their addictive behaviour is wrong. By being told they are morally responsible for their addictive behaviour the addict is being informed of their agency. By being blamed, the addict is being informed their behaviour needs to change, and so blame can be action-guiding. This can enhance the addict's agency and move them toward recovery. So, on the moral model, the addict is a moral agent that can be accurately blamed for their addictive behaviour. And because a degree of agency is required to recover from addiction, the moral model captures something essential for overcoming addiction, namely an addict's agency. Thus, the moral model of addiction is consistent with addressing addiction with compassion rather than harsh treatment or punishment, and its readiness to blame addicts recognizes addicts have the necessary agency required for proper care and success in their recovery.

\section{References}

Pickard, Hanna. (2017). "Responsibility without blame for addiction.” Neuroethics 10, 169-180. Summers, Jesse S. (2015). "What is Wrong with Addiction.” Philosophy, Psychiatry, \& Psychology, 22(1), 25-40. 